\title{
Clinicopathological characteristics and prognostic analysis of Lauren classification in gastric adenocarcinoma in China
}

\author{
Miao-zhen Qiu ${ }^{1 \dagger}$, Mu-yan Cai' ${ }^{2 \dagger}$, Dong-sheng Zhang ${ }^{1}$, Zhi-qiang Wang ${ }^{1}$, De-shen Wang ${ }^{1}$, Yu-hong Li
} and Rui-hua $\mathrm{Xu}^{{ }^{1 *}}$

\begin{abstract}
Background: According to the Lauren classification, gastric adenocarcinomas are divided into diffuse and intestinal types. The causative attribution explaining the dismal prognosis of diffuse-type remains unknown.

Methods: We examined the archive of 1000 patients with gastric adenocarcinomas who received radical gastrectomy in our center and assessed the effect of the Lauren classification on survival in a multivariate approach. Moreover we compared the variation of clinical features between the diffuse-type and intestinal-type and explored the contributing factors for the prognostic difference.

Results: There were 805 resectable patients for the final analysis. Diffuse-type comprised of $48.7 \%$ in the gastric carcinoma in our group and showed poorer prognosis than intestinal-type $(P=0.013)$. Multivariate analysis revealed that independent prognostic factors for gastric carcinoma patients were $T$ stage $(P<0.001)$, N stage $(P<0.001)$ tumor size $(P<0.001)$ and Lauren classification $(P=0.003)$. For the clinical features, diffuse-type was significantly associated with younger age $(p<0.001)$, female preponderance $(p<0.001)$, distal location $(P<0.001)$, advanced $p T(p<0.001)$, advanced $p N(p<0.001)$ and advanced TNM stage $(p=0.027)$.

Conclusions: Diffuse type adenocarcinoma carries a worse prognosis that may be partially explained by the tendency of this subtype to present at more advanced T and N stage. However, Lauren classification has prognostic significance that is independent of $\mathrm{T}$ and $\mathrm{N}$ stage as well as other prognostic variables based on the multivariate cox analysis.
\end{abstract}

Keywords: Gastric cancer, Lauren classification, Prognostic analysis

\section{Background}

About one million people are diagnosed with gastric carcinoma each year all over the world, making it the fourth most common cancer and the second leading cause of cancer related death [1]. The incidence rate of gastric carcinoma varies dramatically from one part of the world to another and it is particularly common in Eastern Asia, including China [2]. The prognosis for gastric adenocarcinoma patients remains poor and our understanding of this cancer entity is still limited.

\footnotetext{
* Correspondence: xurh@sysucc.org.cn

${ }^{\dagger}$ Equal contributors

'State Key Laboratory of Oncology in South China, Department of Medical Oncology, Sun Yat-sen University Cancer Center, Guangzhou 510060, China Full list of author information is available at the end of the article
}

According to the Lauren classification, gastric adenocarcinomas can be divided into two major histological types, diffuse and intestinal type [3]. The intestinal type is characterized by cohesive cells which form gland-like structures, while for the diffuse type, tumor cells lack cell-to-cell interactions and infiltrate the stroma as single cell or small subgroups, leading to a population of non-cohesive, scattered tumor cells [3]. Although the Lauren classification system can date back to 1965 , it is still widely accepted and employed by pathologists and physicians today and represents a simple but robust classification approach. The two Lauren types have several distinct clinical and molecular characteristics, including etiology, carcinogenesis, epidemiology and progression, message ribonucleic acid (mRNA) and / or protein ex-

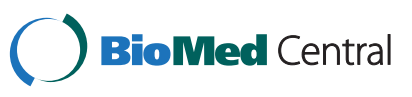


pression profile, microsatellite instability, and mutation profiles [4]. Thus, it is widely accepted that they represent distinct disease entities which may benefit from different therapeutic approaches. In the recent reported clinical trial-Trastuzumab in combination with chemotherapy versus chemotherapy alone for treatment of HER2-positive advanced gastric or gastro-oesophageal junction cancer (ToGA), patients in the control group had a higher overall survival rates than expected [5] and the authors considered that it might be due to the higher percentage of intestinal-type tumors in the control group compared with other phase III studies [6]. It was reported that the expression of human epidermal growth factor receptor-2 (HER2) was more common in intestinaltype tumors and such patients have a better outcome than patients with diffuse-type tumors [7-10]. The importance of Lauren classification took our attention.

The aims of our present study are: (1) to analyze the prognostic value of Lauren classifications in resectable gastric cancer patients in China, (2) to compare the clinicopathological characteristics of diffuse-type and intestinal-type in gastric cancer and identify the clinicopathological factors which may explain the different prognosis of the these two types.

\section{Materials and methods}

\section{Ethics statement}

All patients provided written informed consent for their information to be stored and used in the hospital database. Study approval was obtained from independent ethics committees at Cancer Center of Sun Yat-Sen University. The study was undertaken in accordance with the ethical standards of the World Medical Association Declaration of Helsinki.

\section{Patients}

The medical records of 1000 patients with pathologicallyconfirmed gastric adenocarcinoma between January 1996 and December 2006 were retrospectively analyzed. They all received D2 resection carried out by experienced surgeons in the Cancer Center of Sun Yat-Sen University following the Japanese Gastric Cancer Association (JGCA) guidelines [11]. Both the proximal and distal margins are negative and at least $3 \mathrm{~cm}$ away from the tumor. Besides, the surgeon dissected the station D2 lymph nodes. There is no macroscopic or microscopic residual tumor. The total number of dissected lymph nodes of the 1000 gastric carcinoma patients was 16008 , with an average of $18.8 \pm 5.3$ (means \pm s.d.) dissected nodes per case (median 24.0, range 13-72). The number of excised lymph nodes was less than 15 in $24.2 \%$ of patients who received resection.

We excluded 82 patients $(8.2 \%)$ because of missing baseline characteristics, 75 patients $(7.5 \%)$ younger than 18 years old, 32 patients $(3.2 \%)$ with incomplete follow- up and 6 patients (0.6\%) with secondary malignancy. None of the patients received neoadjuvant treatment. The final study involved 805 patients.

The clinical features collected for subsequent analysis included gender (male or female), age at diagnosis $(<59$ or $\geq 59$ years, the median age was 59$)$, tumor size $(\leq 5 \mathrm{~cm}$ or $>5 \mathrm{~cm}$, the median diameter was $5 \mathrm{~cm}$ ), location of primary tumor (proximal or distal), histology subtypes (well + moderate differentiated adenocarcinoma or poorly + signet ring cell differentiated adenocarcinoma), Lauren classifications (diffuse type or intestinal type), anemia (yes or no), angiolymphatic invasion (yes or no), the TNM staging system (American Joint Committee on Cancer (AJCC) $7^{\text {th }}$ edition) (Table 1$)$.

During the study period we did not have a standardized protocol for postoperative chemotherapy and (or) radiotherapy. Adjuvant therapy was considered in patients with T3-T4 classification and/or positive lymph node involvement. In the present study, only 532 (66.1\%) patients completed the adjuvant chemotherapy (2-6 cycles). Agents using for chemotherapy included oxaliplatin, 5-fluorouracil, capecitabine, S-1, irinotecan, docetaxol and taxol. The median number of cycles was 4. No patients received adjuvant radiotherapy. As of May $1^{\text {st }}$, 2012, 403 patients had died from the disease.

Tissue samples from resected tumors were classified and staged by an experienced pathologist according to the WHO classification and the TNM staging system following general pathological guidelines. Assignment of the histologic type was based on the Lauren criteria. The intestinal type was described as a tumor with glandular architecture, resembling colonic carcinoma; the diffuse type, as a tumor composed of solitary or small clusters of cells, and lacking glandular structures. The mixed type was described as the combination of these two features. Two pathologists reviewed the original diagnostic slides in order to grade, stage and classify the tumors as intestinal or diffuse type.

\section{Statistical analysis}

All statistical analyses were performed by Statistical Package of Social Sciences 13.0 software. $\mathrm{P}$ value $<0.05$ was considered to be statistically significant. The Kaplan-Meier method was used to estimate overall survival. For patients who remained alive, data were censored at the date of the last contact. Kaplan-Meier analysis with log-rank testing was used for univariate analysis. The definition of the overall survival interval was the duration between the date of diagnosis and the date of last contact. Variables showing a trend for association with survival $(\mathrm{P}<0.05)$ and variables that were known to have prognostic value were selected in the final multivariable Cox proportional hazards model, while variables that are highly associated with others were excluded from the final multivariable model. 
Table 1 Demographics and univariate survival analysis results of the $\mathbf{8 0 5}$ gastric carcinoma patients

\begin{tabular}{|c|c|c|c|c|c|c|c|c|}
\hline \multirow{2}{*}{$\begin{array}{l}\text { Factors } \\
\text { Gender }\end{array}$} & \multirow[t]{2}{*}{ Numbers } & \multirow[t]{2}{*}{$\begin{array}{l}5 \text { year survival } \\
\text { rate }(\%)\end{array}$} & \multirow[t]{2}{*}{$P$ value } & \multirow{2}{*}{ IIIA } & \multicolumn{2}{|l|}{82} & \\
\hline & & & & & \multicolumn{2}{|c|}{132} & \multicolumn{2}{|l|}{43.7} \\
\hline Male & 557 & 48.9 & & IIIC & 163 & & 24.3 & $<0.001$ \\
\hline female & 248 & 46.1 & 0.581 & \multicolumn{5}{|c|}{$\begin{array}{l}\text { Abbreviations: AJCC, American Joint Committee on Cancer; TNM, Tumor-Node- } \\
\text { Metastasis. }\end{array}$} \\
\hline \multicolumn{9}{|l|}{ Age median 59} \\
\hline$\leq 59$ & 419 & 50.5 & & & & & & \\
\hline$>59$ & 386 & 45.8 & 0.135 & \multicolumn{5}{|c|}{$\begin{array}{l}\text { Table } 2 \text { Clinicopathologic features and Lauren } \\
\text { classification }\end{array}$} \\
\hline \multicolumn{4}{|l|}{ Lauren classification } & \multirow[t]{2}{*}{ Characteristics } & \multirow{2}{*}{$\begin{array}{c}\text { Total } \\
\text { number }\end{array}$} & \multicolumn{2}{|c|}{ Lauren classification } & \multirow[t]{2}{*}{$P$ value } \\
\hline $\begin{array}{l}\text { Diffuse type } \\
\text { Intestinal type }\end{array}$ & $\begin{array}{l}392 \\
356\end{array}$ & $\begin{array}{l}44.1 \\
52.7\end{array}$ & 0.013 & & & $\begin{array}{l}\text { Diffuse } \\
\text { type }\end{array}$ & $\begin{array}{l}\text { Intestinal } \\
\text { type }\end{array}$ & \\
\hline Tumor size & & & & Age & & & & $<0.001$ \\
\hline$\leq 5 \mathrm{~cm}$ & 483 & 55.2 & & $\leq 59$ & 392 & 246 & 146 & \\
\hline$>5 \mathrm{~cm}$ & 322 & 38.5 & $<0.001$ & $>59$ & 356 & 150 & 206 & \\
\hline Anemia & & & & Sex & & & & $<0.001$ \\
\hline Yes & 247 & 57.4 & & Female & 298 & 211 & 87 & \\
\hline No & 558 & 61.0 & 0.554 & Male & 450 & 181 & 269 & \\
\hline Angiolymphatic invasion & & & & Time period & & & & 0.041 \\
\hline Yes & 52 & 36.5 & & 1996.1-2000.12 & 118 & 72 & 46 & \\
\hline No & 753 & 48.8 & 0.009 & $2001.1-2006.12$ & 630 & 320 & 310 & \\
\hline Location of tumor & & & & Location of tumor & & & & $<0.001$ \\
\hline Proximal & 347 & 42.5 & & Proximal & 326 & 129 & 197 & \\
\hline Distal & 458 & 49.4 & 0.017 & distal & 422 & 263 & 159 & \\
\hline Number of lymph nodes & & & & Size & & & & 0.268 \\
\hline$<15$ & 195 & 46.9 & & $\leq 5 \mathrm{~cm}$ & 453 & 230 & 223 & \\
\hline$\geq 15$ & 610 & 51.4 & 0.233 & $>5 \mathrm{~cm}$ & 295 & 162 & 133 & \\
\hline Type of gastrectomy & & & & The $7^{\text {th }} T$ stage (AJCC) & & & & $<0.001$ \\
\hline Proximal subtotal & 323 & 45.2 & & $\mathrm{~T} 1$ & 61 & 24 & 37 & \\
\hline Distal subtotal & 386 & 56.9 & & $\mathrm{~T} 2$ & 79 & 55 & 24 & \\
\hline Total & 96 & 31.5 & $<0.001$ & T3 & 532 & 260 & 272 & \\
\hline The $7^{\text {th }}$ T stage (AJCC) & & & & $\mathrm{T} 4$ & 76 & 57 & 19 & \\
\hline $\mathrm{T} 1$ & 59 & 88.1 & & The $7^{\text {th }} \mathrm{N}$ stage (AJCC) & & & & $<0.001$ \\
\hline T2 & 87 & 67.8 & & No & 259 & 112 & 147 & \\
\hline T3 & 532 & 45.3 & & N1 & 116 & 52 & 64 & \\
\hline T4 & 127 & 27.5 & $<0.001$ & $\mathrm{~N} 2$ & 161 & 92 & 69 & \\
\hline The $7^{\text {th }} \mathrm{N}$ stage (AJCC) & & & & N3 & 212 & 140 & 72 & \\
\hline No & 269 & 69.0 & & The $7^{\text {th }}$ TNM stage (AJC & & & & 0.027 \\
\hline N1 & 125 & 59.6 & & I & 113 & 47 & 66 & \\
\hline N2 & 179 & 44.0 & & $\|$ & 280 & 146 & 134 & \\
\hline N3 & 232 & 23.0 & $<0.001$ & III & 355 & 199 & 156 & \\
\hline The $7^{\text {th }}$ TNM stage (AJCC) & & & & Histology subtype & & & & $<0.001$ \\
\hline IA & 56 & 86.3 & & Well + Moderate & 281 & 0 & 281 & \\
\hline IB & 70 & 76.9 & & Poor + signet ring cell & 467 & 392 & 75 & \\
\hline$\| \mathrm{A}$ & 96 & 70.7 & & $\begin{array}{l}\text { Abbreviations: AJCC, Am } \\
\text { Metastasis: The analysis }\end{array}$ & Joint Cor & ittee on & cer; TNM, T & $\begin{array}{l}\text { nor-Node- } \\
\text { mixed }\end{array}$ \\
\hline$\| B$ & 206 & 66.2 & & diffuse-intestinal types. & & & & \\
\hline
\end{tabular}

Table 1 Demographics and univariate survival analysis results of the $\mathbf{8 0 5}$ gastric carcinoma patients (Continued)

Abbreviations: AJCC, American Joint Committee on Cancer; TNM, Tumor-Node-

Age median 59

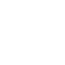


The chi-square test was used to compare the clinicopathologic data.

\section{Results}

\section{Patient demographics}

The median age of the 805 patients was 59 years (ranging from 20 to 84 years old). Among them 557 were male and 248 were female. The overall 5-year survival for the patient population was $48.2 \%$, with a median survival of 53.4 months. The median follow-up for the entire cohort was 42.0 months (range 3.0-173.0 months). The characteristics of the 805 gastric adenocarcinoma patients and the effect of clinical features on survival are summarized in Table 1.

\section{Lauren classification}

There were 396 (49.2\%) patients with diffuse-type and $352(43.7 \%)$ patients with intestinal-type carcinoma. The remaining 57 patients belonged to the mixed-type carcinoma. In the following analysis, we only included the 748 patients with the diffuse-type or intestinal-type carcinoma.

Patient characteristics of the two groups are shown in Table 2. Among intestinal-type carcinoma, 146 (41.5\%) were younger than 60 years old compared to 246 (62.1\%) of patients with diffuse-type carcinoma $(\mathrm{P}<0.001)$. The ratio of male to female was significantly higher in the intestinal-type carcinoma group than that in the diffusetype group, 3.1 vs $0.86(\mathrm{P}<0.001)$. We divided the ten year study period into two groups, the early period: from January 1996 to December 2000, the later period: from January 2001 to December 2006. We found that the ratio between diffuse type to intestinal type decreased from 1.57 (early period) to 1.03 (later period), $\mathrm{P}=0.041$. Among intestinal-type carcinomas, $55.3 \%$ of tumors were located in the proximal stomach compared to $32.9 \%$ of diffusetype carcinomas, $(\mathrm{P}<0.001)$. The mean size of tumors was about $51.6 \mathrm{~mm}$ for diffuse-type carcinomas and $50.2 \mathrm{~mm}$ for intestinal-type, $\mathrm{P}=0.268$. Distribution of T-stage was significantly different between the diffuse-type and the intestinal-type (Table 2). Moreover, for the lymph nodes status, $41.3 \%$ of patients with intestinal-type carcinoma had no evidence of lymph nodes metastasis, while for the diffuse-type carcinoma, the rate of N0 was $28.6 \%$. Besides, the ratio of stage I: II: III was $12.1 \%: 37.2 \%: 50.7 \%$ in the diffuse-type, nevertheless, it was $18.5 \%$ : $37.7 \%$ : $43.8 \%$ in the intestinal-type, $\mathrm{P}=0.027$.

\section{Univariate and multivariable analyses of overall survival}

Both univariate and multivariable analyses were used to evaluate factors relating to overall survival. Factors of Lauren classification, tumor size, angiolymphatic invasion, location of tumor, degree of differentiation, $\mathrm{T}$ stage, $\mathrm{N}$ stage and TNM stage in the AJCC $7^{\text {th }}$ system were

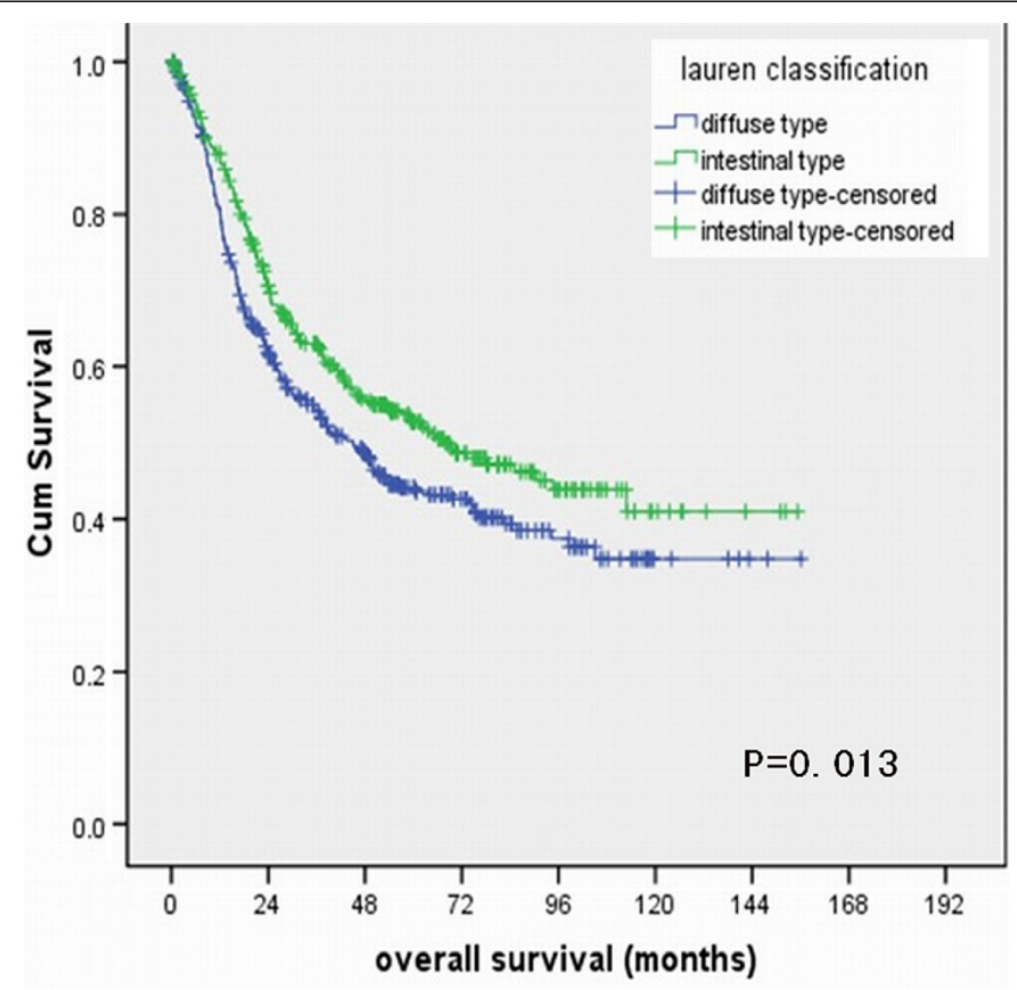

Figure 1 Survival curves of gastric adenocarcinoma patients with diffuse-type and intestinal-type. 
Table 3 Multivariate analysis of overall survival in gastric carcinoma

\begin{tabular}{|c|c|c|c|c|c|}
\hline \multirow[t]{2}{*}{ Factors } & \multicolumn{2}{|c|}{ Characteristics } & \multirow[t]{2}{*}{ Hazard ratio } & \multirow[t]{2}{*}{$95 \% \mathrm{Cl}$} & \multirow[t]{2}{*}{$P$ value } \\
\hline & Unfavorable & Favorable & & & \\
\hline Age & $\geq 59$ & $<59$ & 1.111 & $0.899-1.374$ & 0.328 \\
\hline Gender & Female & Male & 1.057 & $0.843-1.324$ & 0.631 \\
\hline Lauren classification & Diffuse type & Intestinal type & 0.736 & $0.595-0.910$ & 0.005 \\
\hline Histological grade & Poorly & Well/moderately & 1.025 & $0.899-1.167$ & 0.714 \\
\hline Size & $>5 \mathrm{~cm}$ & $\leq 5 \mathrm{~cm}$ & 1.605 & $1.307-1.972$ & $<0.001$ \\
\hline Location & Proximal & Distal & 0.852 & $0.697-1.042$ & 0.120 \\
\hline T stage & $2 / 3 / 4$ & 1 & 1.890 & $1.230-2.746$ & $<0.001$ \\
\hline N stage & $1 / 2 / 3$ & 0 & 1.368 & $1.048-1.894$ & $<0.001$ \\
\hline Angiolymphatic invasion & $(+)$ & $(-)$ & 1.209 & $0.831-1.759$ & 0.321 \\
\hline Type of gastrectomy & Total & Subtotal & 1.135 & $0.859-1.468$ & 0.582 \\
\hline
\end{tabular}

Cl, confidence interval.

significantly associated with overall survival (Table 1). The 5-year overall survival rate of patients with diffuse-type and intestinal type were $44.1 \%$ and $52.7 \%$, respectively, $\mathrm{P}=0.013$ (Figure 1).

For the multivariable regression analysis, only $\mathrm{T}$ stage $(\mathrm{P}<0.001), \mathrm{N}$ stage $(\mathrm{P}<0.001)$, tumor size $(\mathrm{P}<0.001)$ and Lauren classification $(\mathrm{P}=0.003)$ remained independent negative predictors of survival (Table 3 ).

\section{Discussion}

In 1965, Lauren proposed a division of gastric carcinoma into two structurally distinct types, the intestinal-type and the diffuse-type [3]. The former was most frequently seen in men and older patients and the latter had a worse prognosis and was more frequent in women and younger patients. He proposed that these two types could account for approximately $85 \%$ of gastric carcinomas, and the remainder comprised mixed types and other less common histologies. Several studies have found that the Lauren classification is reproducible [12-16]. Our study confirmed the fact that patients with the diffuse-type of gastric carcinoma had poorer prognosis than patients with intestinal type $(\mathrm{P}=0.013)$ in our Chinese patient population. Multivariate analysis revealed that independent prognostic factors for patients with resected gastric adenocarcinoma were TNM stage, tumor size and the Lauren classification. Our previous studies also showed that tumor size was an independent negative predictor of survival in lymph nodes negative gastric carcinoma patients [17]. While the histology was eliminated. Several studies have indicated that patients with intestinal-type tumors had a better outcome than those with diffuse-type tumors [8-10]. The two Lauren types varied in several clinical and molecular characteristics. We tried to seek the difference between these two types in the clinical features which may be responsible for the survival variation.
In our study, diffuse-type gastric carcinoma was significantly associated with younger age $(\mathrm{p}<0.001)$, female preponderance $(\mathrm{p}<0.001)$, distal location $(\mathrm{P}<0.001)$, advanced $\mathrm{pT}(\mathrm{p}<0.001)$, advanced $\mathrm{pN}(\mathrm{p}<0.001)$ and advanced TNM stage $(\mathrm{p}=0.027)$. Though the impact of age, gender and location as prognostic factors was still controversial, it is well accepted that advanced $\mathrm{pN}$ as well as advanced $\mathrm{pT}$ are poor prognostic factors for gastric carcinoma [17-20]. The higher percentage of patients with advanced $\mathrm{pN}$ and advanced $\mathrm{pT}$ subtypes in the diffuse-type gastric carcinoma as compared with the intestinal-type may contribute to the poor prognosis of patients with diffuse-type. Yamashita $\mathrm{K}$ et al. revealed that the more dismal prognosis of diffuse-type gastric carcinoma than intestinal-type could be explained by propensity of deeper invasion and emerging peritoneal cancer cell in the Japanese population [8]. In our study, we demonstrated that high percentage of advanced $\mathrm{pN}$ was also responsible for the poor prognosis of diffuse-type in Chinese patients with resectable gastric carcinoma.

The present study shows that both diffuse-type and intestinal-type carcinoma account for $92.9 \%$ (748/805) of gastric carcinoma in China. Diffuse-type accounted for $48.7 \%(392 / 805)$ of all gastric carcinomas. It was reported that intestinal type was more common in areas with a

Table 4 Ratio of the diffuse type to intestinal type of gastric carcinoma in different areas

\begin{tabular}{lllll}
\hline Area & $\begin{array}{l}\text { Diffuse } \\
\text { type }\end{array}$ & $\begin{array}{l}\text { Intestinal } \\
\text { type }\end{array}$ & $\begin{array}{l}\text { Mixed } \\
\text { type }\end{array}$ & Ratio* \\
\hline Our data & 396 & 352 & 57 & 1.13 \\
Hawaii Japanese $^{16}$ & 144 & 109 & 41 & 1.32 \\
Singapore $^{21}$ & 206 & 405 & 37 & 0.51 \\
Portugal $^{22}$ & 48 & 112 & 12 & 0.43 \\
Finland $^{25}$ & 537 & 729 & 177 & 0.74 \\
\hline
\end{tabular}

* Ratio means the ratio of the diffuse type to intestinal type gastric carcinoma. 
high risk for gastric carcinoma, whereas diffuse type was relatively more common in low-risk areas [13]. The ratio of diffuse and intestinal types of gastric carcinoma in China (1.13) was similar to the Hawaii Japanese population, which was 1.32, while in European countries, such as Finland and Portugal, intestinal type was more common (Table 4) [13,16,21,22].

In our study we found that the intestinal-type was more frequently in males and in elderly patients, while the diffuse-type occurred more frequently in women and young patients. This results confirms the observations of others [12-15]. The 3.6 male:female ratio for the intestinal type and 0.86 ratio for diffuse tumors in our study is comparable to that noted in Fukuoka, Japan, where they were 2.60 and 0.5 respectively [23], and in Hawaii Japanese, where these ratio were 2.39 and 0.86 respectively [18].

In China, not all the patients would go to the same hospital during the course of treatment, maybe after recurrence they would transfer to the local hospital or quit treatment. We tried to get the data of recurrence but some of the patients forgot the date of recurrence. That is why we don't analyze the recurrence free survival.

In our previous study, we showed that as the age increased there was a steady increasing in the proportion of male and steady decreasing of female [24]. Similarly, we presently also found a steady increasing in the ratio between male and female as the age increased. This suggests a positive relationship between the age and the male: female ratio, however the exact nature of the correlation between gender, age and Lauren classifications warrants further study.

In our study, we found a decrease in the ratio between diffuse type to intestinal type over time from 1.57 (from January 1996 to December 2000) to 1.03 (from January 2001 to December 2006), $\mathrm{P}=0.041$. However, Pekka A et al. found that in a Finland based population,the ratio of diffuse-type to intestinal-type increased over time suggesting differences in the epidemiologic shift of gastric carcinomas between Eastern and Western populations [25].

The limitation of current study is its retrospective methodology from a single-institution experience. The impact of various treatments related outcome could not be fully evaluated. Moreover, it is inaccurate to analyze the recurrence free interval. External validation by using other large database for evaluating the prognostic effect of Lauren classification would be of value to further explore the mechanism of different prognosis between diffuse-type and intestinal-type gastric carcinoma.

\section{Conclusion}

The authors are not aware of any previous studies which address the clinicopathological characteristics and prognostic impact of the Lauren classification in patients with resectable gastric cancer in China. In this retrospective study conducted with 805 patients with gastric adenocarcinoma we submit the following conclusions: 1) The combination of TNM staging with Lauren classification and tumor size are the most meaningful prognostic factors. 2) Advanced $\mathrm{pN}$ as well as advanced $\mathrm{pT}$ appear to account for the poor prognosis of diffuse-type in Chinese patients with resectable gastric carcinoma.

\section{Abbreviations}

mRNA: Messenger ribonucleic acid; ToGA: Trastuzumab in combination with chemotherapy versus chemotherapy alone for treatment of HER2-positive advanced gastric or gastro-oesophageal junction cancer; HER2: Human epidermal growth factor receptor-2; JGCA: Japanese gastric cancer association; AJCC: American joint committee on Cancer; WHO: World health organization; TNM: Tumor-node-metastasis.

\section{Competing interests}

We have no financial or personal relationships with other people or organizations that would bias our work. No benefits in any form have been received or will be received from a commercial party related directly or indirectly to the subject of our article. We declare that we have no competing interests.

\section{Authors' contributions}

MZQ participated in the clinical data collecting of the gastric carcinoma patients and drafted the manuscript. MYC and MZQ reviewed the pathologic slices and decided the Lauren classification. DSZ performed the statistical analysis. ZQW participated in the design of the study. DSW and YHL participated in the statistical analysis. RHX conceived of the study, and participated in its design and coordination and helped to draft the manuscript. All authors read and approved the final manuscript.

\section{Authors' information}

Miao-zhen Qiu and Mu-yan Cai are co-first authors.

\section{Acknowledgements}

We gratefully thank Professor Liu Qing in the epidemiology department for his suggestion in the statistical analysis. Besides, we thank Sharlene Gill in the department of Medical Oncology, BC Cancer Agency, Vancouver, Canada to help us correct the grammatical and stylistic errors throughout the manuscript.

\section{Author details}

${ }^{1}$ State Key Laboratory of Oncology in South China, Department of Medical Oncology, Sun Yat-sen University Cancer Center, Guangzhou 510060, China. ${ }^{2}$ State Key Laboratory of Oncology in South China, Department of Pathology, Sun Yat-sen University Cancer Center, Guangzhou 510060, China.

Received: 6 September 2012 Accepted: 20 February 2013

Published: 6 March 2013

\section{References}

1. Kamangar F, Dores GM, Anderson WF: Patterns of cancer incidence, mortality, and prevalence across five continents: defining priorities to reduce cancer disparities in different geographic regions of the world. J Clin Oncol 2006, 24:2137-50.

2. Moore MA, Eser S, Igisinov N, Igisinov S, Mohagheghi MA, Mousavi-Jarrahi A, Ozentürk G, Soipova M, Tuncer M, Sobue T: Cancer epidemiology and control in North-Western and Central Asia - past, present and future. Asian Pac J Cancer Prev 2010, 11:17-32.

3. Lauren P: The two histologic main types of gastric carcinoma: diffuse and so-called intestinal type carcinoma. An attempt at a histo-clinical classification. Acta Parhol Microbid Scan 1965, 64:31-49.

4. Vauhkonen M, Vauhkonen H, Sipponen P: Pathology and molecular biology of gastric cancer. Best Pract Res Clin Gastroenterol 2006, 20:651-674.

5. Bang YJ, Van Cutsem E, Feyereislova A, Chung HC, Shen L, Sawaki A, Lordick F, Ohtsu A, Omuro Y, Satoh T, Aprile G, Kulikov E, Hill J, Lehle M, Rüschoff J, Kang YK, ToGA Trial Investigators: Trastuzumab in combination 
with chemotherapy versus chemotherapy alone for treatment of HER2 positive advanced gastric or gastro-oesophageal junction cancer (ToGA): a phase 3, open-label, randomized controlled trial. Lancet 2010, 376:687-697.

6. Van Cutsem E, Moiseyenko VM, Tjulandin S, Majlis A, Constenla M, Boni C, Rodrigues A, Fodor M, Chao Y, Voznyi E, Risse ML, Ajani JA, V325 Study Group: Phase III study of docetaxel and cisplatin plus fluorouracil compared with cisplatin and fluorouracil as first-line therapy for advanced gastric cancer: a report of the V325 Study Group. J Clin Oncol 2006, 24:4991-4997.

7. Tanner M, Hollmén M, Junttila TT, Kapanen Al, Tommola S, Soini Y, Helin H, Salo J, Joensuu H, Sihvo E, Elenius K, Isola J: Amplification of HER-2 in gastric carcinoma: association with Topoisomerase II alpha gene amplification, intestinal type, poor prognosis and sensitivity to trastuzumab. Ann Oncol 2005, 16:273-278.

8. Yamashita K, Sakuramoto S, Katada N, Futawatari N, Moriya H, Hirai K, Kikuchi S, Watanabe M: Diffuse type advanced gastric cancer showing dismal prognosis is characterized by deeper invasion and emerging peritoneal cancer cell: the latest comparative study to intestinal advanced gastric cancer. Hepatogastroenterology 2009, 56:276-281.

9. Miyahara R, Niwa Y, Matsuura T, Maeda O, Ando T, Ohmiya N, Itoh A, Hirooka Y, Goto H: Prevalence and prognosis of gastric cancer detected by screening in a large Japanese population: data from a single institute over 30 years. J Gastroenterol Hepatol 2007, 22:1435-1442.

10. Zheng H, Takahashi H, Murai Y, Cui Z, Nomoto K, Miwa S, Tsuneyama K, Takano Y: Pathobiological characteristics of intestinal and diffuse-type gastric carcinoma in Japan: an immunostaining study on the tissue microarray. J Clin Pathol 2007, 60:273-277.

11. Japanese Gastric Cancer Association: Japanese classification of gastric carcinoma-2nd English edition. Gastric Cancer 1998, 1:10-24.

12. Correa P, Cuello C, Duque E: Carcinoma and intestinal metaplasia of the stomach in Colombian migrants. J Natl Cancer Inst 1970, 44:297-306.

13. Muñoz N, Correa P, Cuello C, Duque E: Histologic types of gastric carcinoma in high- and low-risk areas. Int J Cancer 1968, 3:809-818.

14. Stalsberg $\mathrm{H}$ : Histological typing of gastric carcinoma. A comparison of surgical and autopsy materials, and of primary tumours and metastases. Acta Pathol Microbiol Scand A 1972, 80:509-514.

15. Kim KH, Chi CH, Lee SK, Lee D, Kubo T: Histologic types of gastric carcinoma among Koreans. Cancer 1972, 29:1261-1263.

16. Stemmermann GN, Brown C: A survival study of intestinal and diffuse types of gastric carcinoma. A survival study of intestinal and diffuse types of gastric carcinoma. Cancer 1974, 33:1190-1195.

17. Qiu MZ, Wang ZQ, Luo HY, Zhang DS, Zhou ZW, Li YH, Jiang WQ, Xu RH: Prognostic analysis in node-negative gastric cancer patients in China. Tumour Biol 2011, 32:489-492.

18. Förster S, Gretschel S, Jöns T, Yashiro M, Kemmner W: THBS4, a novel stromal molecule of diffuse-type gastric adenocarcinomas, identified by transcriptome-wide expression profiling. Mod Pathol 2011, 24:1390-1403.

19. Qiu MZ, Wang ZQ, Zhang DS, Liu Q, Luo HY, Zhou ZW, Li YH, Jiang WQ, Xu $\mathrm{RH}$ : Comparison of 6th and 7th AJCC TNM staging classification for carcinoma of the stomach in China. Ann Surg Oncol 2011, 18:1869-1876.

20. Qiu MZ, Han B, Luo HY, Zhou ZW, Wang ZQ, Wang FH, Li YH, Xu RH: Expressions of hypoxia-inducible factor-1 $1 \mathrm{a}$ and hexokinase-II in gastric adenocarcinoma: the impact on prognosis and correlation to clinicopathologic features. Tumour Biol 2011, 32:159-166.

21. Teh M, Lee Y-S: Intestinal and diffuse carcinoma of the stomach cancer among the ethnic and dialectic groups in Singapore. Cancer 1987, 60:921-925.

22. Ribeiro MM, Sarmento JA, Sobrinho Simões MA, Bastos J: Prognostic significance of Lauren and Ming classifications and other pathologic parameters in gastric carcinoma. Cancer 1981, 47:780-784.

23. Yamamoto T, Kato H: Two major histological types of gastric carcinoma among the fixed population of Hiroshima and Nagasaki. Gann 1971, 62:381-387.

24. Qiu MZ, Wang ZQ, Zhang DS, Luo HY, Zhou ZW, Wang FH, Li YH, Jiang WQ, $\mathrm{Xu}$ RH: Clinicopathological characteristics and prognostic analysis of gastric cancer in the young adult in China. Tumour Biol 2011, 32:509-514

25. Amorosi A, Palli D: Epidemiology of intestinal and diffuse types of gastric carcinoma: a time-trend study in Finland with comparison between studies from high- and low-risk areas. Cancer 1994, 73:1533.

\section{Submit your next manuscript to BioMed Central and take full advantage of:}

- Convenient online submission

- Thorough peer review

- No space constraints or color figure charges

- Immediate publication on acceptance

- Inclusion in PubMed, CAS, Scopus and Google Scholar

- Research which is freely available for redistribution 